\title{
The researcher as hooligan: where 'participant' observation means breaking the law
}

\author{
Geoff Pearson* \\ Management School, University of Liverpool, Liverpool, UK
}

\begin{abstract}
This article focuses on the problems faced by researchers carrying out participant observation in fields where the committal of criminal offences is the norm. Can participation in criminal activity by a researcher be justified on the grounds that it is necessary to prevent the distortion of the field? Alternatively, can the difficulties in gaining and maintaining access in such spheres excuse such conduct? The article considers the current guidance given to researchers in the social sciences and the peculiar pressures placed on them when carrying out fieldwork in 'criminal' areas. Examples from the author's own experiences carrying out covert participant observation within crowds of 'risk' football supporters are used to illustrate that in such fields the committal of offences can be unavoidable and that further guidance - but not regulation - is required to protect academics carrying out this type of research.
\end{abstract}

Keywords: ethics; participant observation; criminality; football hooliganism

\section{Introduction}

This article looks at the unique problems that researchers face carrying out participant observation (PO) in fields where criminal activity is commonplace and where 'participation' can often mean breaking the law. It does not intend to revisit the well-worn arguments concerning the ethics of covert participant observation (CPO), although as we will see, many of the same debates about proportionality and justifiability arise. The merits, dilemmas and ethical problems arising from CPO have already provoked much academic debate (e.g. Bulmer, 1982; Crow, Wiles, Heath, \& Charles, 2006; Erikson, 1967), and bodies such as the British and American Sociological Associations and the ESRC have felt obliged to draft codes and frameworks stating the desired objectives and minimum standards of social research, resulting in increased ethical regulation (Crow et al., 2006, p. 85). This guidance suggests that academic researchers in the social sciences should adhere to ethical standards based around principles such as informed consent, anonymity of research subjects and an adherence to standards of conduct that will not damage the reputation of academia or endanger subsequent researchers. However, whilst this is desirable, some have argued that in exceptional situations, non-adherence to these guidelines to allow covert research may be justifiable in situations where the field would otherwise be closed to research, where overt techniques would unduly distort the field leading to inaccurate results, or where the safety of the researcher is at stake (e.g. Denzin \& Erikson, 1982).

*Email: pearsong@liv.ac.uk 
This position is supported to some extent by the codes themselves. For example, the Statement of Ethical Practice for the British Sociological Association states that 'the use of covert methods may be justified in certain circumstances'. ${ }^{1}$ Similarly, the ESRC Research Ethics Framework notes that where researchers pursue projects where informed consent is not gained this must be justified: 'Deception (i.e. research without consent) should only be used as a last resort when no other approach is possible'. ${ }^{2}$ The British Society of Criminology Code of Ethics is even more stringent, noting that the 'exceptional circumstances' in which research without informed consent could be justified relate 'to exceptional importance of the topic rather than difficulty of gaining access'. 3

These limited exceptions to the general ethical standards suggest that where it is impossible to pursue avenues of 'ethical' research, methods such as CPO can be undertaken, provided every effort is undertaken to prevent harm befalling the research subjects (e.g. by preserving anonymity). The codes point to a balance between the beneficial outcomes of research on the one hand, and the potential 'harm' caused by methods such as CPO on the other. Essentially the issue is one of proportionality: where the 'harm' is minimal (e.g. a minor infringement of the right to privacy) and the research beneficial, the research is justifiable, but where methods cause serious harm (e.g. the reporting of the research subject to the police), it is more difficult for the research to be justified by its outcomes. A research method that causes harm but delivers little public benefit, we can assume, would be considered disproportionate and therefore unjustifiable.

However, do these arguments about proportionality and justifiability apply to the dilemma of researchers being pressurised to commit criminal offences in the field in the course of obtaining research findings? This is a predicament that researchers studying criminal or quasi-criminal social groups frequently face, particularly those involved in PO. In these fields, research subjects are often mistrustful of academics, whom they may believe will report them to the authorities (see Armstrong, 1993, especially pp. 23-25; Stott, Hutchinson, \& Drury, 2001, p. 364). This can lead the observer (particularly one who possesses no previous connection with those under observation) to commit criminal offences during participation in order to integrate into the field and gain the trust of the subjects. Unlike the utilisation of covert methods, the issue of criminality is not expressly referred to in the ethical codes, although it can be presumed through reading them that academics are expected to abide by the law whilst carrying out their research. 4

The question I wish to address is whether the committal of criminal offences is ever justifiable in social research and what guidance should be given to researchers operating in these fields. Should we assume that unlawful methods are always unethical? If so, do the same arguments of proportionality apply to this problem as are applied to the use of covert research methods in the codes? After all, the admission that covert methods are sometimes justifiable is controversial. In private research spheres in particular, the covert researcher essentially wilfully misleads research subjects who have not consented to being observed, invading their privacy. It also potentially puts non-consenting subjects in danger, for example, should the authorities compel the researcher to surrender research data or testify in a court of law (see Coomber, 2002). Furthermore, the requirement in the codes that the primary concern when covert methods are used should be to avoid harming the subjects places researchers under pressure not to report crimes that are being planned or committed (e.g. Feenan, 2002; Norris, 1993), making the observer complicit in these offences. If 
deception and the hiding of criminal offences from the authorities can be justified where the research field is otherwise inaccessible and/or the findings are in the public interest, then should the same principles apply to the actual committal of offences in the field?

The dilemma of whether or not to commit offences in the course of research arose in my own socio-legal ethnographic study into legislative and policing responses to crowds of 'risk' English football supporters (commonly referred to as 'hooligans'), which was carried out between 1995 and 2007. This research was not exclusively limited to the activities of hardcore 'hooligan' firms in the manner of, for example, Armstrong's work with 'the Blades' (Armstrong, 1998). However, early attempts at interviews proved to be unreliable; often non-violent fans would exaggerate their involvement in disorder whilst serious 'hooligans' tended to 'play-down' their involvement for fear of being reported. Direct observations were therefore required, but my desire first not to distort a field, partly populated by groups of fans committing criminal offences, and second to remain anonymous to police and ground stewards (combined with the general distrust of the fans towards researchers) meant that CPO was adopted.

In order to gain entrance to the field and then maintain a useful research position within it, I found myself both witnessing criminal offences and being put under pressure to commit them personally. This article does not intend to justify my own methodology. Indeed, there were a number of strategies adopted in my earlier research that I would now consider very difficult to defend. I would not claim that my method of approaching the dilemma was the 'right way'. The contradictions and inconsistencies of my own approach will become apparent. Instead, I seek to problematise my own research practice in retrospect to draw out the dilemmas and ethical conundrums that researchers face whilst operating within these kinds of fields. Examples from this fieldwork are included to illustrate the discussion of where the committal of criminal offences fits into the general debate on ethics in fieldwork. Reference will also be made to a number of other ethnographers who have worked in criminal or quasicriminal fields, for example, Armstrong (football 'hooligans' 1998), Drury and Stott (anti-roads protesters, 2001), Hobbs (petty criminals, 1996; armed robbers, 1995), Hobbs, Hadfield, Lister, and Winlow (bouncers, 2003), Patrick (gangs, 1973) and Williams, Dunlap, Johnson, and Ansley (crack users and dealers, 1992).

\section{Criminal offences in football crowds}

It is inevitable that carrying out CPO in groups involved in criminal activity means the researcher will face pressure to participate in the committal of offences. If the true identity and purpose of the researcher is unknown, and s/he is gaining acceptance from the research subjects through participation in their activities then a choice presents itself. Should the researcher commit offences in line with their participation in earlier non-criminal activities of the group? If the researcher follows this path then their position in the research field will be maintained (or even enhanced should suspicions remain about the researcher). This may lead to the subjects being more forthcoming and honest to the researcher, allowing the collection of richer and more accurate data. Furthermore, where the researcher commits an offence that the research subjects are participating in, s/he may also be preventing undue distortion of the field and the damaging of observational data. However, if the researcher refuses to commit the offence, then their 'undercover' position may become threatened where the subjects 
become suspicious as to their motive, which could lead to a loss of the research position. In some cases, this could also result in a threat to the researcher's safety. Even if the research position is maintained, the refusal to participate in the offence has the potential to distort the field by altering the dynamic of the group and making some research subjects 'think twice' about committing the crime. ${ }^{5}$

A number of ethical and practical issues need to be addressed when making this decision. First, should an academic researcher pursuing knowledge 'to serve the public good ${ }^{\prime 6}$ commit criminal offences that in the short term would not be conducive to this aim? If the researcher breaks the law, is s/he bringing their reputation, that of their employer/funder and even the academic profession itself, into disrepute? The second issue is the practicality of committing criminal offences whilst carrying out research, most notably the risk of arrest, prosecution and negative publicity for the researcher's institution/funder.

The committal of offences by researchers embarking on PO (including overt observations) is nothing new, and a number of academics have admitted committing crimes whilst carrying out research. Armstrong, for example, admitted 'two feeble attempts at punching' and running and 'chasing' with the research group whilst carrying out ethnographic research with a 'hooligan firm' (Armstrong, 1993, p. 17), and Drury was amongst a crowd of 12 protesters arrested for breach of the peace whilst carrying out PO at an anti-roads protest (Drury \& Stott, 2001, p. 61). Other researchers have decided not to commit offences. Patrick, for example, felt forced to withdraw from the field (a study of gangs in Glasgow) because he resisted being drawn into escalating violence (Patrick, 1973, pp. 135-139). Polsky also argues that the researcher must 'draw a line' between her/himself and the 'criminal':

... in doing field research on criminals you damned well better not pretend to be 'one of them', because they will test this claim out and one of two things will happen: either you will (...) get sucking into 'participant' observation of the sort you would rather not undertake, or you will be exposed, with still greater negative consequences. $\left(1969\right.$, p. 124) ${ }^{7}$

However, despite the dilemma not being a new one, little guidance is provided by the codes and frameworks on ethical research conduct. Initially my own research adopted a phenomenological position, stating that the only way I could gain an understanding of the 'lifeworld' of the subjects was to fully immerse myself in the group's activities through PO (see Bruyn, 1970, pp. 69-70, p. 204; Sellitz et al., 1965, p. 283), which would include participation in any offences they may commit. Such a course of action would have put me, the research subjects and the reputation of my institution in serious jeopardy and I felt a compromise had to be found. In the field of football-crowd disorder, research subjects frequently commit a wide range of mainly lower level criminal offences, the most typical being: drink and drug offences, ticket touting, breaches of the Football (Offences) Act 1990 (invading the pitch, throwing missiles, indecent or racialist chanting), disorderly and threatening behaviour, assault and actual bodily harm, theft and criminal damage. Additionally, the groups would on occasion commit more serious offences such as riot, affray, violent disorder, robbery and assault occasioning grievous bodily harm.

Whilst it was possible to avoid committing some individual offences, a refusal to commit crimes on a regular basis would have aroused suspicions and reduced research opportunities. As a result, I committed 'minor' offences (which I tentatively defined as those which would not cause direct physical harm to a research subject) on a weekly 
basis as part of the research routine. My strategy was to commit only the offences which the majority of the research subjects were committing and that I considered necessary to carry out the research. Furthermore, whilst I would commit lesser offences with regularity I would, if possible, avoid more serious ones. In practice, this strategy was not as simple to follow as first envisaged, and on numerous occasions I found myself straying from it either on the basis of my personal morals or to maintain or enhance my position in the field. There follows three examples taken from a threeyear period (ending in 1998) carrying out covert research with fans of an English football club for my $\mathrm{PhD}$ thesis that illustrate some of the aforementioned dilemmas. The work was initially self-funded and at no stage was I required to gain ethical clearance, although I was encouraged to be ethically reflexive about my methods. These examples demonstrate the rationale for my decisions - i.e. to enable me to gather rich, undistorted empirical data that would otherwise have been inaccessible.

\section{'Accessing the field' in a literal sense}

During my period in the field, the research subjects frequently invaded the football pitch in my presence. Legislation makes any infringement onto the pitch an arrestable criminal offence and under certain circumstances it can be construed as threatening behaviour under the Public Order Act. One extreme example of this practice occurred when approximately 400 fans (including the 'risk supporters' under observation) scaled perimeter fencing and massed on the side of the pitch as a match drew to a close. At the other end of the stadium, rival fans were also climbing the fences to invade the pitch and the police were preparing a large-scale deployment. It was clear that a confrontation was going to occur and that the best place to observe the intricacies of the confrontation and policing would be on the pitch. Therefore, I joined the supporters on their charge across the pitch at the final whistle that resulted in them chasing the home supporters (who simultaneously invaded the playing field) back into their own stand. My positioning on the pitch, rather than watching lawfully from the stands, enabled me to pick up the mood of the supporters involved in the 'charge' (many fans, for example, became distressed when they realised the celebratory charge was turning disorderly). It also enabled me to witness first-hand the actions of the police officers one of whom seized me and threatened me with arrest if I did not return to the stands immediately. In line with the actions of research subjects I had observed in similar interactions, I followed the officer's advice, on this occasion preventing possible embarrassment for myself and my institution.

\section{'This train has been designated alcohol-free'}

Another football-specific criminal offence I committed was taking and consuming alcohol on 'football specials' (i.e. transport organised to carry visiting supporters to matches). ${ }^{8}$ This is a low-level offence that is frequently committed by fans and when I was travelling with 'risk supporters', it was expected that alcohol would be taken onto transport. Smuggling alcohol past the police and drinking on football specials proved to be an important method of encouraging social interaction, which in turn led to increased opportunities for data collection. Finally, the process of attempting to smuggle alcohol onto football specials proved an excellent way of testing the effectiveness of this public order tactic, demonstrating that where supporters were determined to breach the legislation, they would usually be successful. Furthermore, I approached the 
research from a socio-legal perspective which, in contrast to positivist legal approaches, encourages critical analysis of the basis and utilisation of laws such as this. From an early stage of my research, I became highly critical of the provisions of the Sporting Events (Control of Alcohol etc.) Act 1985, considering it badly drafted, rushed legislation that caused more public order problems than it solved (Pearson, 2000). As a result, I had no moral qualms about breaching this statute, and found little criticism from my academic peers. However, that is not to say that such activity was therefore justifiable, or would have been considered acceptable by my institution.

\section{'You're a bit of a nutter!'}

The most serious dilemma I encountered was where I considered it necessary to commit an offence that the research subjects were not participating in at the relevant time. This is difficult to justify because the 'distorting the field' argument cannot be used. For individual observations and non-covert work, it is difficult to think of occasions when this would be necessary but my own covert research with a particular group of supporters over an extended period provided new challenges. For short periods of covert research, it is easier to avoid committing offences, or to 'pick and choose' which offences to commit. Issues of trust between the subjects and the researcher are less complex and researchers can either avoid committing offences, or are able to risk 'pretending' to commit them (e.g. miming offensive chanting in a crowd).

However, during longer periods of covert research, these tactics for avoiding the committal of individual offences are more difficult to apply. Whilst avoiding participation in disorder in which research subjects are involved on a few occasions may not endanger the field position, acting in this way over a number of months will inevitably lead to questions and suspicions arising that could lead to a loss of the research position. In groups of 'risk supporters', this can be particularly problematic in the aftermath of undercover police operations and the recent indiscreet revelations of covert journalists with hidden cameras. ${ }^{9}$ As a result, the covert researcher needs to act in line with research subject norms over the entire period of research if $\mathrm{s} / \mathrm{he}$ wishes to retain trust and access. This obviously puts the researcher under greater pressure to commit criminal acts, but at the same time provides the opportunity to 'opt out' of some actions, provided that $\mathrm{s} /$ he has already gained the trust of the research subjects.

The pressure I faced to commit minor offences such as those noted above was always present, but I was usually able to avoid committing the more serious offences provided that trust was maintained when my behaviour was viewed over a longer period. As a result, on several occasions, I committed offences that, whilst recognisable to the sub-culture of the research subjects, were not always in keeping with what was occurring in the field at that given moment. I took this action when I was concerned that there were suspicions about my conduct that could risk my research position particularly where I had 'opted out' of crimes committed by the subjects (or where I intended to in the future), usually because I considered them unacceptable risks to the safety of myself or other research subjects, or because I feared identification by the authorities. ${ }^{10}$ On one occasion, for example, when I believed it necessary to prove my reliability to the subjects, I individually confronted a small group of rival supporters in a public house. The attempt was purely 'for show' as I predicted the group would intervene and prevent any serious physical confrontation. Nonetheless, the action was both criminal (threatening behaviour) and in the short term seriously 
distorted the field. ${ }^{11}$ My justification for this action at the time was that it enhanced my position in the field and I was accepted for the remainder of the season as one of the 'hardcore' despite my continual 'opting out' of more serious offences. In fact, towards the end of this research period, I was informed by one of the research subjects that I was considered to be 'a bit of a nutter' by some of the group. This was despite the fact that during my entire time in the field, I had not 'connected' with a single punch nor been arrested, in contrast to many of the research subjects.

This example demonstrates the extremes of the dilemma of the covert participant observer working for long periods of time in 'criminal' fields. A methodology which required the researcher to carry out such actions may well fail to get ethical clearance by a University or funding body. However, in closing the door to this type of research strategy, the possibility of carrying out an ethnographic analysis of an undistorted field without a highly increased risk of physical harm (and arrest) would be closed. Without taking such actions, future observations would have needed to be external and of an overt nature. This, in turn, may have distorted the field and increased the chances of observer misinterpretation of events and the motives/actions of the research subjects. I considered that my actions were justifiable in terms of research data gained from a closed field which over the years has been much misunderstood, and from research subjects who have been subject to serious injustices and maltreatment by those in authority (see Armstrong \& Hobbs, 1994; Giulianotti, 1994; Greenfield \& Osborn, 1996; James \& Pearson, 2006; Pearson, 1998, 1999, 2006; Scraton, Jemphrey, \& Coleman, 1995; Stott \& Pearson, 2006). The data gathered fed into findings that were publicised in academic publications, books, newspaper articles, radio and television, highlighting these injustices. Later, work in the area as part of a larger project relying in part on similar methods fed directly into police practice which resulted in a significant reduction in both disorder and arrests at international football tournaments (Stott \& Pearson, 2007). However, in terms of arguing that 'the end justified the means', it should be kept in mind that the extent of this impact could not have been predicted when I initially embarked upon the research. My initial overriding intention was not to publicise injustices or change things 'for the better' but merely to gain suitable data for my $\mathrm{PhD}$ thesis! So attempting to justify research methods on utilitarian grounds of harm and benefit is problematic as we can never be sure of the positive impact our research will have (nor, indeed, of the scale of the harm that may arise).

\section{Consistency, guidance and academic freedom}

Even if we accept that the type of strategies I followed could be justified (either by their necessity or their outcomes), my approach could still be criticised due to a severe lack of consistency. At no stage was I able to determine and justify hard-and-fast rules about what offences I would commit and when. My justifications were initially based on the 'distortion of the field' argument, that I would do everything that was necessary to reduce distortion of the field by my own presence. However, personal ideas of ethics and morality impinged upon this and there were some specific offences that I refused to commit purely for these reasons. For example, I refused to indulge in racist chanting, even though in the eyes of the law this is considered less serious than other offences I committed. Practical pressures meant that I also avoided other offences, particularly when my crowd observations were combined with interviews with police officers and football officials who were present on the ground. My decision not to 
follow the 'distortion of the field' argument through to its logical conclusion therefore endangered both the quality of my data and my position in the field. It also damaged my ability to justify some of the unethical methods used during my research as it weakened the claim that committing specific offences was absolutely necessary to carry out the research.

There are a number of approaches that could be adopted when dealing with these issues. The first is to claim that guidance, regulation and consistency about what offences can be committed and under what circumstances is unnecessary, and that decisions about conduct in the field should depend upon the conscience of the individual researcher. It can be argued that hard-and-fast rules unduly hamper research and that only the researcher her/himself knows the unique problems and dilemmas that will arise in their field. Reynolds (1982), for example, argues that it is up to the researcher to determine how s/he wishes to 'serve society' (i.e. whether knowledge itself is an end or whether personal morality is of greater importance), suggesting that a Kantian view of following 'universal' moral rules is not the only way to determine the researcher's conduct. ${ }^{12}$

This argument suggests that it should be the researcher who determines: (1) the importance of their own research to academia and society, and (2) whether any ethical infringements are justified in this light. With the current ethical codes proving to be ineffective in providing clear and unambiguous guidance to researchers embarking on research into criminal fields, this is essentially the current situation (except in cases where applications for funding are carefully vetted and/or where ethical clearance is required). However, this position provides little protection for the individual researcher when it comes to criticism of their methods by their institution, potential funders or the media. It also provides no support whatsoever in the event of an investigation or prosecution by the authorities. Moreover, such an approach invites criticism where it is perceived that a researcher has an inflated opinion of the value of their own work or where s/he considers 'unethical' behaviour to be less problematic than colleagues (e.g. Warwick's (1982) criticism of Humphreys, especially p. 56).

An alternative approach would be to adopt the ethical norms of the research field, in other words, to follow the lead of research subjects in terms of what offences to commit and what to avoid. This stance is supported by Hobbs (1996) who adopted it in his participant observational study of 'wheelers and dealers' in London's East End. Hobbs participated in the field even when this meant involvement in criminal activity, but argued this was not unethical because the ethics adopted were those of the community. He argued that his research necessitated '... a willingness to abide by the ethics of the researched culture and not the normative ethical constraints of sociological research' and that 'a failure to adhere to these norms would have closed the research field' (1996, p. 7). This stance could easily be applied in the field of football-crowd disorder because those involved typically follow sub-cultural norms that the committal only of certain crimes, or in certain contexts, is acceptable. ${ }^{13}$

However, this approach also has problems in that it could reduce the opportunity for covert research in areas of more serious criminality, which it can be argued (due to their severity) are in greater need of academic exposure and analysis. Adhering to Hobbs's line in the research of, for example, a 'paedophile ring' would be unlikely to be seen as justifiable by third parties (particularly the media), however beneficial the research outcome.

A third approach is for better guidelines to be laid down by research bodies and institutions about how work in controversial and potentially dangerous fields should 
be conducted, most obviously by adding to the current codes of practice. Academic peers have a legitimate interest in how research is carried out by others; unethical conduct by colleagues may harm participants, damage the reputation of a department, organisation or institution and make future research in similar areas more difficult, so it is easy to argue that such research should be more heavily regulated. If codes could be re-drafted to include more guidance on research in criminal fields this could theoretically open up research funding to fields that are currently under-researched due to the difficulty of obtaining ethical clearance from funders relying on the current codes. Another advantage of set rules is that this could provide some protection for researchers, particularly against investigation or punishment for the committal of offences in the course of research. Whilst it is not suggested that additions to the codes could - or should - grant any form of guaranteed 'immunity' from prosecution, it would provide some guidance and protection for researchers in this area that would be beneficial in the event of threats of litigation, employment disputes with institutions or investigations by the media.

Unfortunately in the current climate such a development looks unrealistic and here lies a fundamental 'Catch-22'. There are serious problems with the current codes that make the addition of more 'hard-and-fast' rules problematic. The codes are not universally accepted as appropriate frameworks for researchers in the social sciences; Homan, for example, criticised them as being more likely to close discussion on ethical issues rather than stimulate it (1991, p. 38). More recently Hammersley has expressed concern about the role of current codes and ethical committees, noting their tendency to rely upon medical and psychological models that are not always appropriate for social sciences (2006, p. 5; see also Coomber, 2002 with specific reference to informed consent) and arguing that ethical committees are not always in the best position to determine what research should proceed. It is also argued that 'hard-and-fast' rules are not always the best way to approach questions of methodology and ethics, particularly in areas where access is impossible by overt methods (Crow et al., 2006, p. 88) and that as a result ' $\ldots$ the rigidity of standardised regulation will need to be tempered by a degree of flexibility according to the characteristics of specific research contexts' (p. 95). Increased regulation of covert fieldwork in such fields would almost certainly see reduced freedom for academics carrying out such research. Funders and institutions wary of their legal and public relations position would be unlikely to give approval to proposals that could see a researcher risk prosecution or media expose. Additionally, legal obligations under Health and Safety Legislation would make it difficult for an institution to sanction the taking of risks in the field that may lead to physical injury.

In light of these legal and practical realities, the solution may be not increased regulation through codes and ethics committees, but increased non-binding guidance for researchers considering utilising such methods. New researchers in particular could be made aware of the ethical and practical problems with such methods (as well as their potential technical advantages) and more comprehensive research training modules could provide guidance and 'lessons from the field' from those who have used such methods (in the manner of Williams et al.'s (1992) work on personal safety in research). Researchers should be encouraged to adopt strategies to minimise threats such as by carrying out risk assessments, and made aware of the pressures on institutions and funders. They should also be encouraged to be self-aware of the limitations of their own research in terms of justifying contentious methods and encouraged to be forward thinking and open about the actual potential value their research will have 
above and beyond their acquisition of a $\mathrm{PhD}$ and/or publications in high-ranking academic journals. However, such guidance must fall short of preventing such methods being adopted where no other 'ethical' method could be employed to achieve the same results and senior colleagues and research committees should be wary of determining that projects are not 'worthy' of utilising contentious methods.

\section{Conclusion}

Little formal guidance is provided to researchers in the social sciences who wish to carry out ethnographic research within 'criminal' fields. If current ethical guidelines, relying on principles such as informed consent, are applied to research proposals in such areas, the research methods that can be utilised are dramatically reduced. However, in areas of criminality, where distrust of authority figures is commonplace, often methods such as CPO can be the only way of gaining meaningful and undistorted data. Ethical codes in the social sciences acknowledge that such methods can be used 'as a last resort' but give little guidance either to individual researchers or ethics committees on how such methods can be used in practice. In particular, how should covert observers act when faced with the pressure to commit offences themselves?

If we accept that the purpose of academic research is to advance knowledge, rather than to serve any particular dominant moral standpoint, then covert methods should be justifiable if they achieve the aim of enhancing understanding of otherwise 'hidden' areas. Furthermore, where we accept that this legitimate aim can justify covert methods, we also need to acknowledge that in many cases, this will lead to the researcher acting illegally within these fields. It seems illogical to permit covert activity in fields of criminality but not accept that the researcher may have to commit occasional unlawful acts. Without the freedom to make these choices, CPO in these areas will be hamstrung. There are some areas of society to which the overt researcher will not be permitted and to which the covert researcher will never be accepted unless $\mathrm{s} /$ he participates in activities which would be considered unacceptable according to traditional ethical standards. However, these areas should not be out of bounds for the researcher and, if properly managed, the potential value of research into these areas can offset the risks to both individual and institution.

'Criminal' research fields are deserving of serious academic analysis and the adoption of the most appropriate research method to provide the best data. Without researchers who are willing to embark upon covert research, and are sometimes willing to break the law in order to gather this data, some aspects of society will remain hidden or misunderstood, with negative consequences for those in, or affected by, those areas. In the long term, 'protecting' the research subjects by prohibiting covert methods may have the opposite effect, keeping harm and injustices hidden from the public. It will also reduce the value of academic research generally in terms of 'making a difference', as researchers are steered towards topics that are as 'mundane' as possible (Crow et al., 2006, p. 89).

However, the current situation, whereby researchers operating in these fields often 'go it alone' by justifying their own methods results in difficulties and dangers. Such a situation grants important academic freedom to researchers who are not bound by ethical clearance procedures, but the risks that come with operating in this way should not be underestimated by either researcher or institution. As a result, further guidance for those who consider it is necessary to adopt such strategies is important in order to 
guide their ethical decisions. This guidance could be used to provide some protection from critical employers or funders and in some cases, police forces, state prosecution services and the courts. However, such guidance should not in the present climate materialise in the form of extended frameworks or codes of practice, which have been criticised for being overly restrictive on methods and closing debate on contentious subjects. There is a difference between guidance and increased regulation. The latter, in the current climate, would almost certainly reduce the freedom to carry out research in areas where fieldwork is required to understand phenomena and drive forward social change. Until the issues and dangers of such methods are further debated and illuminated, some research areas will remain closed and other researchers will continue to operate in potentially dangerous research fields without adequate risk assessment or guidance.

\section{Notes}

1. 2002, s. 31. Similar statements are contained within the Socio-Legal Studies Association First Re-Statement of Research Ethics (s. 6.6(2)) and the American Sociological Association's Code of Ethics 1999 (s. 12.01(b)).

2. Para 3.2.2.

3. 2006, s. 4(iii).

4. For example with reference to the reporting of offences against children and the right to privacy.

5. The participant observer must, of course, also be careful that their participation does not encourage offences that may otherwise have not been committed.

6. American Sociological Association Code of Ethics 1999 Principle E.

7. Although Homan points out that Polsky removed symbols of the social researcher and suggests he may not have been as open as he claimed (1991, p. 120).

8. Prohibited by the Sporting Events (Control of Alcohol etc.) Act 1985.

9. Such as the 'McIntyre Investigates' (BBC1, 9 November 1999) and 'Hooligans: A Panorama Special' (BBC1, 2 August 2006).

10. This was a particular concern as my research increasingly saw covert observation combined with interviews/observations with the police, Home Office and football authorities.

11. Although conversely in doing so it led to rich data about the ability of groups of risk supporters to 'self police'.

12. Suggested other methods that could be used include cost/benefit analyses and a balancing of the individual rights of research subjects against the rights of society.

13. For example, the 'unwritten rule' that fighting fellow 'risk supporters' is acceptable, but attacking ordinary fans and members of the public is not.

\section{Notes on contributor}

Geoff Pearson is a lecturer in law at the University of Liverpool Management School. He has carried out ethnographic research into the policing of football crowds since 1995 and is co-author of Football Hooliganism: Policing and the War on the English Disease, London: Pennant Books, 2007.

\section{References}

Armstrong, G. (1993). Like that Desmond Morris? In D. Hobbs \& T. May (Eds.), Interpreting the field - Accounts of ethnography (pp. 3-44). Oxford: Oxford University Press.

Armstrong, G. (1998). Football hooligans: Knowing the score. Oxford: Berg.

Armstrong, G., \& Hobbs, D. (1994). Tackled from behind. In R. Giulianotti, N. Bonney, \& M. Hepworth (Eds.), Football, violence and social identity (pp. 196-228). London: Routledge. Bruyn, S. (1970). The new empiricists: The participant observer and the phenomenologist. In W. Filstead (Ed.), Qualitative methodology: Firsthand involvement with the social world (pp. 283-287). Chicago, IL: Markham. 
Bulmer, M. (1982). The merits and demerits of covert participant observation. In M. Bulmer (Ed.), Social research ethics (pp. 217-251). New York: Holmes \& Meier.

Coomber, R. (2002). Protecting our research subjects, our data and ourselves from respective prosecution, seizure and summons/subpoena. Addiction Research and Theory, 10(1), 1-5.

Crow, G., Wiles, R., Heath, S., \& Charles, V. (2006). Research ethics and data quality: The implications of informed consent. International Journal of Social Research Methodology, 9(2), 83-95.

Denzin, N., \& Erikson, K. (1982). On the ethics of disguised observation. In M. Bulmer (Ed.), Social research ethics (pp. 142-151). New York: Holmes \& Meier.

Drury, J., \& Stott, C. (2001). Bias as a research strategy: The case of intergroup conflict. Field Methods, 13(1), 47-67.

Erikson, K. (1967). A comment on disguise observation in sociology. Social Problems, 14, $366-373$.

Feenan, D. (2002). Researching paramilitary violence in northern Ireland. International Journal of Social Research Methodology, 5(2), 147-163.

Giulianotti, R. (1994). Taking liberties: Hibs casuals and Scottish law. In R. Giulianotti, N. Bonney, \& M. Hepworth (Eds.), Football, violence and social identity (pp. 229-261). London: Routledge.

Greenfield, S., \& Osborn, G. (1996). After the act: The (re)construction of football fandom. Journal of Civil Liberties, 1(1), 7-28.

Hammersley, M. (2006). Are ethical committees ethical? Qualitative Researcher, 2, 4-8.

Hobbs, D. (1995). Bad business: Professional crime in modern Britain. Oxford: Oxford University Press.

Hobbs, D. (1996). Doing the business: Entrepreneurship, detectives and the working class in the east end of London. Oxford: Clarendon.

Hobbs, D., Hadfield, P., Lister, S., \& Winlow, S. (2003). Bouncers: Violence and governance in the night-time economy. Oxford: Oxford University Press.

Homan, R. (1991). The ethics of social research. London: Longman.

James, M., \& Pearson, G. (2006). Football banning orders: Analysing their use in court. Journal of Criminal Law, 70(6), 509-530.

Norris, C. (1993). Some ethical considerations on field-work with the police. In D. Hobbs \& T. May (Eds.), Interpreting the field - Accounts of ethnography (pp. 122-144). Oxford: Oxford University Press.

Patrick, J. (1973). A Glasgow gang observed. London: Eyre-Methuen.

Pearson, G. (1998). The English disease? The socio-legal construction of football hooliganism. Youth and Policy - The Journal of Critical Analysis, (60), 1-15.

Pearson, G. (1999). Legitimate targets? The civil liberties of football fans. Journal of Civil Liberties, 4(1), 28-47.

Pearson, G. (2000). Legislating for the football hooligan: A case for reform. In S. Greenfield \& G. Osborn (Eds.), Law and Sport in Contemporary Society (pp. 182-200). London: Frank Cass.

Pearson, G. (2006). Contextualising the football disorder act: Proportionality under the hammer. In S. Greenfield \& G. Osborn (Eds.), Readings in law and popular culture (pp. 91-118). London: Routledge.

Polsky, N. (1969). Hustlers, beats and others. Harmondsworth: Penguin.

Reynolds, P. (1982). Moral judgements: Strategies for analysis with application to covert participant observation. In M. Bulmer (Ed.), Social research ethics (pp. 185-216). New York: Holmes \& Meier.

Scraton, P., Jemphrey, A., \& Coleman, S. (1995). No last rights: The denial of justice and the promotion of myth in the aftermath of the Hillsborough disaster. Liverpool: LCC/Alden Press.

Sellitz, C., Jahoba, H., Deutsch, M., \& Cook, S. W. (1965). Research methods in social relations. London: Methuen.

Stott, C., Hutchinson, P., \& Drury, J. (2001). 'Hooligans' abroad? Inter-group dynamics, social identity and participation in collective 'disorder' at the 1998 World Cup finals. British Journal of Social Psychology, 40, 359-384.

Stott, C., \& Pearson, G. (2006). Football banning orders, proportionality and public order. Howard Journal of Criminal Justice, 45(3), 241-254. 
Stott, C., \& Pearson, G. (2007). Football 'hooliganism', policing and the war on the 'English disease'. London: Pennant Books.

Warwick, D. (1982). Tearoom trade: Means and ends in social research. In M. Bulmer (Ed.), Social research ethics (pp. 38-58). New York: Holmes \& Meier.

Williams, T., Dunlap, E., Johnson, B., \& Ansley, H. (1992). Personal safety in dangerous places. Journal of Contemporary Ethnography, 21(3), 343-374. 
Copyright of International Journal of Social Research Methodology is the property of Routledge and its content may not be copied or emailed to multiple sites or posted to a listserv without the copyright holder's express written permission. However, users may print, download, or email articles for individual use. 